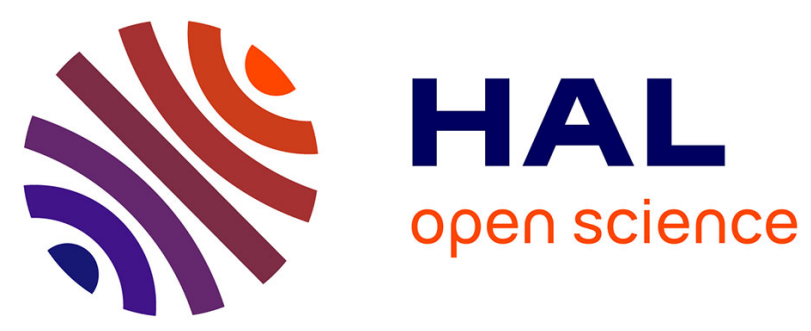

\title{
High-pressure High-temperature Synthesis, Magnetic Properties and X-ray Absorption Spectroscopy of Phases RE3Sn7 and hp-RESn3-x (RE = Tb, Ho, Er)
}

Katrin Meier, Leonid Vasylechko, Raul Cardoso-Gil, Ulrich Burkhardt, Walter Schnelle, Marcus Schmidt, Yuri Grin, Ulrich Schwarz

\section{To cite this version:}

Katrin Meier, Leonid Vasylechko, Raul Cardoso-Gil, Ulrich Burkhardt, Walter Schnelle, et al.. High-pressure High-temperature Synthesis, Magnetic Properties and X-ray Absorption Spectroscopy of Phases RE3Sn7 and hp-RESn3-x $(\mathrm{RE}=\mathrm{Tb}, \mathrm{Ho}, \mathrm{Er})$. Journal of Inorganic and General Chemistry / Zeitschrift für anorganische und allgemeine Chemie, 2010, 636 (9-10), pp.1695. 10.1002/zaac.201000147 . hal-00552475

\section{HAL Id: hal-00552475 https://hal.science/hal-00552475}

Submitted on 6 Jan 2011

HAL is a multi-disciplinary open access archive for the deposit and dissemination of scientific research documents, whether they are published or not. The documents may come from teaching and research institutions in France or abroad, or from public or private research centers.
L'archive ouverte pluridisciplinaire HAL, est destinée au dépôt et à la diffusion de documents scientifiques de niveau recherche, publiés ou non, émanant des établissements d'enseignement et de recherche français ou étrangers, des laboratoires publics ou privés. 


\section{Zeitschrift für Anorganische und}

Allgemeine Chemie

\section{High-pressure High-temperature Synthesis, Magnetic Properties and X-ray Absorption Spectroscopy of Phases RE3Sn7 and hp-RESn3-X (RE = Tb, Ho, Er)}

\begin{tabular}{|c|c|}
\hline Journal: & Zeitschrift für Anorganische und Allgemeine Chemie \\
\hline Manuscript ID: & zaac.201000147.R1 \\
\hline Wiley - Manuscript type: & Article \\
\hline $\begin{array}{r}\text { Date Submitted by the } \\
\text { Author: }\end{array}$ & 27-Apr-2010 \\
\hline Complete List of Authors: & $\begin{array}{l}\text { Meier, Katrin; MPI CPfS, Chemical Metals Science } \\
\text { Vasylechko, Leonid; Lviv PNU, Semiconductor Electronics } \\
\text { Cardoso-Gil, Raul; MPI CPfS, Chemical Metals Science } \\
\text { Burkhardt, Ulrich; MPI CPfS, Chemical Metals Science } \\
\text { Schnelle, Walter; MPI CPfS, Chemical Metals Science } \\
\text { Schmidt, Marcus; MPI CPfS, Chemical Metals Science } \\
\text { Grin, Yuri; MPI CPfS, Chemical Metals Science } \\
\text { Schwarz, Ulrich; MPI CPfS, Chemical Metals Science }\end{array}$ \\
\hline Keywords: & high-pressure synthesis, tin, terbium, holmium, erbium \\
\hline
\end{tabular}

\section{S ScholaroNE" \\ Manuscript Central}




\title{
High-pressure High-temperature Synthesis, Magnetic Properties and X-ray Absorption Spectroscopy of Phases $R E_{3} \mathrm{Sn}_{7}$ and $\mathrm{hp}-R E \mathrm{Sn}_{3-\mathrm{x}}(R E=\mathrm{Tb}, \mathrm{Ho}, \mathrm{Er})$
}

\author{
Katrin Meier $^{[\mathrm{a}]}$, Leonid Vasylechko ${ }^{[\mathrm{a}, \mathrm{b}]}$, Raul Cardoso-Gil ${ }^{[\mathrm{a}]}$, Ulrich Burkhardt ${ }^{[\mathrm{a}]}$, Walter \\ Schnelle $^{[a]}$, Marcus Schmidt ${ }^{[a]}$, Yuri Grin ${ }^{[a]}$ and Ulrich Schwarz ${ }^{[a]}$
}

Dedicated to Prof. Dr. Bernd Harbrecht on the Occasion of his $60^{\text {th }}$ Birthday

Keywords: terbium; holmium; erbium; tin; high-pressure synthesis

\begin{abstract}
The high-temperature high-pressure syntheses of binary phases hp$R E \mathrm{Sn}_{3-\mathrm{x}}(R E=\mathrm{Tb}, \mathrm{Ho}, \mathrm{Er})$ was reinvestigated showing good agreement with previously determined stability fields concerning pressure and temperature conditions. Phases hp-RESn $n_{3-\mathrm{x}}$ adopt a cubic $\mathrm{Cu}_{3} \mathrm{Au}$ arrangement $\left(a=466.52(6) \mathrm{pm}\right.$ for $\mathrm{hp}-\mathrm{TbSn}_{3-\mathrm{x}}$; $a=465.44(8) \mathrm{pm}$ for $\mathrm{hp}-\mathrm{HoSn}_{3-\mathrm{x}}$ and $a=464.98(9) \mathrm{pm}$ for hp$\left.\mathrm{ErSn}_{3-\mathrm{x}}\right)$. Superstructure reflections observed in experiments with synchrotron radiation indicate an ordered arrangement for $\mathrm{HoSn}_{3-\mathrm{x}}$ prepared at 8.4(8) GPa and $1270 \mathrm{~K}$ (space group $P m \overline{3} \mathrm{~m}$ ). hp$\mathrm{HoSn}_{3-\mathrm{x}}$ transforms exothermally at $460 \mathrm{~K}$ and ambient pressure into the low-pressure modification $\mathrm{HoSn}_{3-\mathrm{x}}$ indicating that the ordered $\mathrm{Cu}_{3} \mathrm{Au}$-type arrangement is a metastable high-pressure phase.

A second set of phases are identified as compounds $R E_{3} \operatorname{Sn}_{7}(R E=$ $\mathrm{Ho}$, Er) being isotypic to the ambient pressure modifications $\mathrm{Gd}_{3} \mathrm{Sn}_{7}$ and $\mathrm{Tb}_{3} \mathrm{Sn}_{7}$ (space group Cmmm; lattice parameters $a=434.95(7) \mathrm{pm}, b=2615.6(6) \mathrm{pm}, c=442.09(7) \mathrm{pm}$ for $\mathrm{Ho}_{3} \mathrm{Sn}_{7}$
\end{abstract}

PD Dr. Ulrich Schwarz

Fax: + 35146464002

E-mail: schwarz@cpfs.mpg.de

[a] Max-Planck-Institut für Chemische Physik fester Stoffe, Nöthnitzer Straße 40, 01187 Dresden, Germany

[b] Semiconductor Electronics Department, Lviv Polytechnic National University, 12 Bandera St., 79013 Lviv, Ukraine

\section{Introduction}

In the context of recent high-pressure high-temperature syntheses of new binary silicon- and germanium-rich intermetallic compounds [1-11], the tin-rich parts of the phase diagrams $R E-\mathrm{Sn} \quad(R E=\mathrm{Tb}, \mathrm{Ho}, \mathrm{Er})$ were reinvestigated. An earlier study reports on the formation of cubic close packed $\mathrm{Cu}_{3} \mathrm{Au}$-type phases $R E \mathrm{Sn}_{3}(R E=\mathrm{Tb}$, Ho, Er) at high-pressure high-temperature conditions [12]. Lowering of the synthesis pressure yielded hitherto unidentified products.

At ambient pressure the tin-richest compounds in the binary systems $R E-\mathrm{Sn} \quad(R E=\mathrm{Tb}, \mathrm{Ho}, \mathrm{Er})$ have the composition $R E \mathrm{Sn}_{3-\mathrm{x}}$. At slightly lower tin contents, phases with a composition $R E_{2} \mathrm{Sn}_{5}$ have been described for $R E=$ Ho and $\mathrm{Er}$ while for $R E=\mathrm{Tb}$ a $\mathrm{Gd}_{3} \mathrm{Sn}_{7}$-like orthorhombic crystal structure [13] was observed. This atomic pattern comprises a manifold of different tin coordination and $a=434.29(5) \mathrm{pm}, b=2607.2(4) \mathrm{pm}, c=441.49(5) \mathrm{pm})$ for $\left.\mathrm{Er}_{3} \mathrm{Sn}_{7}\right)$. The crystal structure of compounds $R E_{3} \mathrm{Sn}_{7}$ are interpreted as an intergrowth of $\mathrm{AlB}_{2^{-}}, \mathrm{CaF}_{2^{-}}$and $\mathrm{AuCu}_{3}$-like segments. Analysis of the chemical bonding in $\mathrm{Er}_{3} \mathrm{Sn}_{7}$ by means of the electron localizability approach reveals two-centre $\mathrm{Sn}-\mathrm{Sn}$ bonding in the $\mathrm{AlB}_{2}$-like segment and multi-centre bonding in the $\mathrm{AuCu}_{3}$ - and $\mathrm{CaF}_{2}$-like motifs.

The electrical resistivity of $\rho \approx 31 \mu \Omega \mathrm{cm}$ at $300 \mathrm{~K}$ reveals that $\mathrm{hp}-\mathrm{HoSn}_{3-\mathrm{x}}$ is a metallic conductor. The phases hp-RESn $\mathrm{Sn}_{3-\mathrm{x}}$ and $R E_{3} \mathrm{Sn}_{7} \quad(R E=\mathrm{Ho}, \mathrm{Er})$ show paramagnetic Curie-Weiss behaviour of the rare earth metal ions $\mathrm{Ho}^{3+}$ and $\mathrm{Er}^{3+}$, respectively. $\mathrm{Ho}_{3} \mathrm{Sn}_{7}$ and $\mathrm{Er}_{3} \mathrm{Sn}_{7}$ order antiferromagnetically at $10.0 \mathrm{~K}$ and $8.2 \mathrm{~K}$, respectively. The high-pressure phases $R E \mathrm{Sn}_{3-\mathrm{x}}$ show no magnetic order above $2 \mathrm{~K}$. XAS measurements on the compounds $\mathrm{Tb}_{3} \mathrm{Sn}_{7}$ and $\mathrm{hp}-\mathrm{TbSn}_{3-\mathrm{x}}$ indicate a $4 f^{8}$ configuration evidencing the oxidation state +3 for terbium.

environments ranging from coordination number seven via nine to twelve [14].

Complete definitions of stability fields in high-pressure high-temperature synthesis have to address a threedimensional parameter space with the consequence that even a course grid with respect to each variable would result in a large number of experiments. Thus, the present investigation focuses on the characterisation of the prepared phases $R E_{3} \mathrm{Sn}_{7}$ and hp-RESn $\mathrm{Sn}_{3-\mathrm{x}}$ with regards to crystal structure and composition as well as electrical conductivity and magnetic susceptibility. Additionally, thermal decomposition at ambient pressure will be discussed for $\mathrm{hp}-\mathrm{HoSn}_{3-\mathrm{x}}$ in the context of in-situ X-ray diffraction experiments.

\section{Results and Discussion}

\section{Compounds $\mathrm{RE}_{3} \mathrm{Sn}_{7}(\mathrm{RE}=\mathrm{Tb}, \mathrm{Ho}, \mathrm{Er})$}

At ambient pressure, arc melting of samples with compositions Ho: Sn between $1: 2.2$ and $1: 3$ results in mixtures of phases isotypic to $\mathrm{HoSn}_{2}$ [15] and a tin-rich solid solution $\operatorname{Sn}(\mathrm{Ho})$ with $\beta$-Sn structure. Subsequent highpressure high-temperature treatments basically confirm the earlier phase diagrams [12], e.g., the formation of an hitherto unidentified orthorhombic phase and a tin-rich solid solution $\mathrm{Sn}(\mathrm{Ho})$ at $2 \mathrm{GPa}$ and a temperature of $720 \mathrm{~K}$ for starting compositions Ho : Sn between $1: 2.2$ and $1: 2.85$. 
Determining the chemical composition of the product $\mathrm{Ho}_{3} \mathrm{Sn}_{7}$ (starting composition $1: 2.33$ ) by EDXS (Fig. 1 top) results in a Ho: Sn ratio of $1: 2.31(5)$. The low-pressure phase in the system $\mathrm{Tb}-\mathrm{Sn}$ is identified as $\mathrm{Tb}_{3} \mathrm{Sn}_{7}$ which can be synthesized already at ambient pressures [14]. Energy dispersive X-ray spectroscopy (EDXS) of a polished sample grown in a tin flux at $1370 \mathrm{~K}$ and ambient pressure (annealing time $96 \mathrm{~h}$ ) indicates a composition $\mathrm{Tb}: \mathrm{Sn}=1: 2.22(8)$ in satisfactory agreement with a ratio of $1: 2.33$ calculated for a composition $3: 7$ (Fig. 1 bottom). Conditions for the syntheses of compounds $R E_{3} \mathrm{Sn}_{7}$ $(R E=\mathrm{Tb}, \mathrm{Ho}, \mathrm{Er})$ are summarized in Table 1.

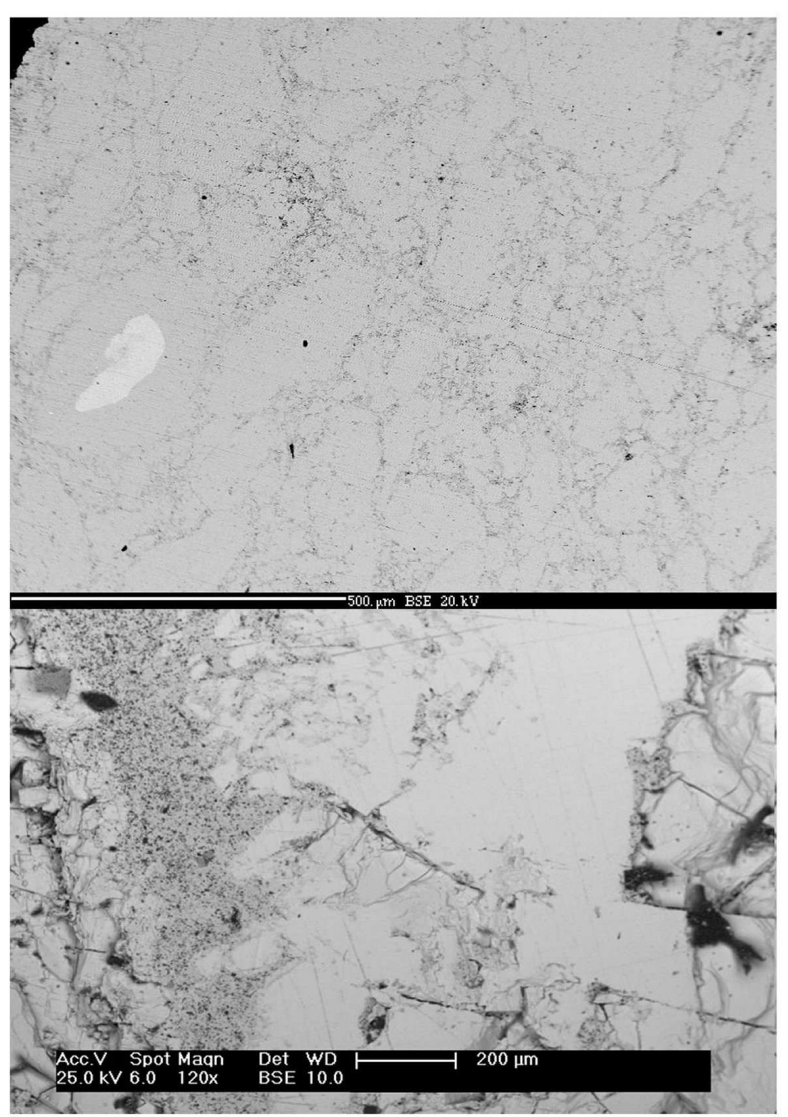

Fig. 1. Electron back scattering images of compounds $R E_{3} \mathrm{Sn}_{7}$ $(R E=\mathrm{Ho}, \mathrm{Tb})$. Top: Sample with a nominal composition Ho : Sn $3: 7$ showing the main phase $\mathrm{Ho}_{3} \mathrm{Sn}_{7}$ (grey), tin-rich solid solution (dark spots) and Ho:Sn $1: 0.60(1)$ (bright spot on the left). Bottom: $\mathrm{Tb}_{3} \mathrm{Sn}_{7}$ grown in a tin flux. The main phase is light grey, dark spots represent tin-rich solid solution. On the left, residuals of the crucible are visible.

Table 1. Starting composition, $P, T$-reaction conditions, identified phases and composition of the reaction products as determined by EDXS for syntheses of compounds $R E_{3} \mathrm{Sn}_{7}(R E=\mathrm{Tb}, \mathrm{Ho}, \mathrm{Er})$.

\begin{tabular}{llll}
\hline $\begin{array}{l}\text { Starting } \\
\text { Composition }\end{array}$ & $\begin{array}{l}T / \mathrm{K} \\
P / \mathrm{GPa}\end{array}$ & Phases & $\begin{array}{l}\text { Composition } \\
\text { EDX }\end{array}$ \\
\hline $\mathrm{Tb}: \mathrm{Sn}$ & 1370 & $\mathrm{~Tb}_{3} \mathrm{Sn}_{7}$ & $1: 2.22(8)$ \\
$1: 7$ & 0.0001 & $\mathrm{Sn}(\mathrm{Ho})$ & \\
\hline $\mathrm{Tb}: \mathrm{Sn}$ & 920 & $\mathrm{~Tb}_{3} \mathrm{Sn}_{7}$ & \\
$1: 3$ & $1.0(1)$ & $\mathrm{Sn}(\mathrm{Ho})$ & \\
\hline $\mathrm{Ho}: \mathrm{Sn}$ & 720 & $\mathrm{Ho}_{3} \mathrm{Sn}_{7}$ & $1: 2.31(5)$ \\
$1: 2.2-2.85$ & $2.0(2)$ & $\mathrm{Sn}^{(\mathrm{Ho})}$ & \\
& & $\mathrm{Ho}_{1.6} \mathrm{Sn}$ & $1: 0.60(1)$ \\
\hline $\mathrm{Er}: \mathrm{Sn}$ & 1078 & $\mathrm{Er}_{3} \mathrm{Sn}_{7}$ & \\
$1: 2.33$ & $5.0(5)$ & $\mathrm{Sn}(\mathrm{Ho})$ & \\
\hline
\end{tabular}

After subtracting the contributions of the phase with $\beta$-Sntype crystal structure from the mixtures, the remaining $\mathrm{X}$ ray powder diffraction lines can be indexed on the basis of an orthorhombic lattice. A comparison of experimental and calculated intensities indicates crystal structures isotypic to the ambient pressure modification of $\mathrm{Gd}_{3} \mathrm{Sn}_{7}$ or $\mathrm{Tb}_{3} \mathrm{Sn}_{7}[13$, 14]. Crystallographic data and refinement results for the synthesized phases $R E_{3} \mathrm{Sn}_{7}(R E=\mathrm{Tb}, \mathrm{Ho}, \mathrm{Er})$ are shown in Table 2 and Table 3.

Table 2. Crystallographic data and refinement parameters of compounds $R E_{3} \mathrm{Sn}_{7}(R E=\mathrm{Tb}, \mathrm{Ho}, \mathrm{Er})$ using the ordered model of $\mathrm{Gd}_{3} \mathrm{Sn}_{7}$ [13] (see Fig .2) Refinement of a disordered $\mathrm{Tb}_{3} \mathrm{Sn}_{7}$-type model [14] did not result in a significant improvement concerning residuals or displacement parameters.

\begin{tabular}{|c|c|}
\hline Temperature, $\mathrm{K}$ & $296(2)$ \\
\hline \multirow[t]{2}{*}{ Diffractometer type } & Huber Image Plate \\
\hline & Guinier Camera G670 \\
\hline Wavelength / Å & $1.54056\left(\mathrm{Cu} K \alpha_{1}\right)$ \\
\hline Crystal system & orthorhombic \\
\hline Space group (No.); $Z$ & Cmmm (65); 2 \\
\hline \multirow[t]{2}{*}{$\begin{array}{l}\mathrm{Tb}_{3} \mathrm{Sn}_{7} \text { : unit cell parameters / } \mathrm{pm} \text {; } \\
\text { unit cell volume } / 10^{6} \mathrm{pm}^{3}\end{array}$} & $\begin{array}{l}a=436.6(1) \\
b=2634.1(1)\end{array}$ \\
\hline & $c=443.7(1) ; V=510.28$ \\
\hline $\mathrm{Ho}_{3} \mathrm{Sn}_{7}$ : unit cell parameters / pm; & $a=4.3495(7)$ \\
\hline \multirow[t]{2}{*}{ Unit cell volume $/ 10^{6} \mathrm{pm}^{3}$} & $b=26.156(6)$ \\
\hline & $c=4.4209(7) ; V=502.95$ \\
\hline $\mathrm{Er}_{3} \mathrm{Sn}_{7}:$ unit cell parameters / pm; & $a=4.3429(5)$ \\
\hline \multirow[t]{2}{*}{ Unit cell volume / $10^{6} \mathrm{pm}^{3}$} & $b=26.072(4)$ \\
\hline & $c=4.4149(5) ; V=499.89$ \\
\hline Measurement range / Degree & $15<2 \Theta<85$ \\
\hline$N($ meas $)(R E=\mathrm{Tb}, \mathrm{Ho}, \mathrm{Er})$ & $14984 ; 14184 ; 13984$ \\
\hline Reflections $(R E=\mathrm{Tb}, \mathrm{Ho}, \mathrm{Er})$ & $140,141,139$ \\
\hline Refinement method & Full profile (Rietveld) \\
\hline Refined structure parameters & 14 \\
\hline$R_{\mathrm{wp}}(R E=\mathrm{Tb}, \mathrm{Ho}, \mathrm{Er})$ & $0.107,0.101,0.099$ \\
\hline$R_{\mathrm{P}}(R E=\mathrm{Tb}, \mathrm{Ho}, \mathrm{Er})$ & $0.160,0.123,0.110$ \\
\hline$R_{\mathrm{I}}(R E=\mathrm{Tb}, \mathrm{Ho}, \mathrm{Er})$ & $0.083,0.085,0.086$ \\
\hline
\end{tabular}

Table 3. Atomic coordinates and isotropic displacement parameters of compounds $R E_{3} \mathrm{Sn}_{7}(R E=\mathrm{Tb}, \mathrm{Ho}, \mathrm{Er})$.

\begin{tabular}{lcllll}
\hline Atom & $\begin{array}{c}\text { Wyckoff } \\
\text { position }\end{array}$ & $x$ & \multicolumn{1}{c}{$y$} & $z$ & $\begin{array}{c}U_{\text {iso }} / \\
10^{4} \mathrm{pm}^{2}\end{array}$ \\
\hline Tb1 & $2 d$ & 0 & 0 & $1 / 2$ & $0.011(1)$ \\
Tb2 & $4 i$ & 0 & $0.3115(1)$ & 0 & $0.014(1)$ \\
Sn1 & $2 b$ & $1 / 2$ & 0 & 0 & $0.011(1)$ \\
Sn2 & $4 j$ & 0 & $0.4043(1)$ & $1 / 2$ & $0.009(1)$ \\
Sn3 & $4 i$ & 0 & $0.0955(1)$ & 0 & $0.009(1)$ \\
Sn4 & $4 j$ & 0 & $0.2123(1)$ & $1 / 2$ & $0.008(1)$ \\
\hline Ho1 & $2 d$ & 0 & 0 & 0 & $0.012(1)$ \\
Ho2 & $4 i$ & 0 & $0.3102(1)$ & 0 & $0.008(1)$ \\
Sn1 & $2 b$ & $1 / 2$ & 0 & 0 & $0.017(2)$ \\
Sn2 & $4 j$ & 0 & $0.4041(1)$ & $1 / 2$ & $0.012(1)$ \\
Sn3 & $4 i$ & 0 & $0.0948(1)$ & 0 & $0.007(1)$ \\
Sn4 & $4 j$ & 0 & $0.2100(1)$ & $1 / 2$ & $0.014(1)$ \\
\hline Er1 & $2 d$ & 0 & 0 & $1 / 2$ & $0.003(1)$ \\
Er2 & $4 i$ & 0 & $0.3106(1)$ & 0 & $0.007(1)$ \\
Sn1 & $2 b$ & $1 / 2$ & 0 & 0 & $0.013(1)$ \\
Sn2 & $4 j$ & 0 & $0.4029(1)$ & $1 / 2$ & $0.008(1)$ \\
Sn3 & $4 i$ & 0 & $0.0957(1)$ & 0 & $0.011(1)$ \\
Sn4 & $4 j$ & 0 & $0.2108(1)$ & $1 / 2$ & $0.011(1)$ \\
\hline
\end{tabular}


The crystal structure of the compounds $R E_{3} \mathrm{Sn}_{7}$ may be interpreted as an intergrowth $[17,18]$ of $2 \mathrm{D}$ segments of the structural patterns of $\mathrm{AlB}_{2}\left(R E \mathrm{Sn}_{2}\right)$ and $\mathrm{AuCu}_{3}\left(R E \mathrm{Sn}_{3}\right)$ prototypes [19] in the ratio 1:1 (Fig. 2). They are separated by fragments adopting the $\mathrm{CaF}_{2}$ motif $\left(R E \mathrm{Sn}_{2}\right)$. The total composition of the unit cell can thus be expressed as $\left[R E \mathrm{Sn}_{2}\right]_{4}\left[R E \mathrm{Sn}_{3}\right]_{2}=R E_{6} \mathrm{Sn}_{14}$. Within the $\mathrm{AlB}_{2}$ segments, tin atoms are located in the centre of trigonal prisms formed by $R E$ atoms and form zig-zag-like chains along the [100] direction. Characteristic features of the $\mathrm{CaF}_{2^{-}}, \mathrm{AuCu}_{3^{-}}$and $\mathrm{AuCu}$-like segments are rectangular networks formed either by $\mathrm{Sn}$ atoms alone or by a mixture of $\mathrm{Sn}$ and $R E$ atoms in the ratio 1:1 (Fig. 2).

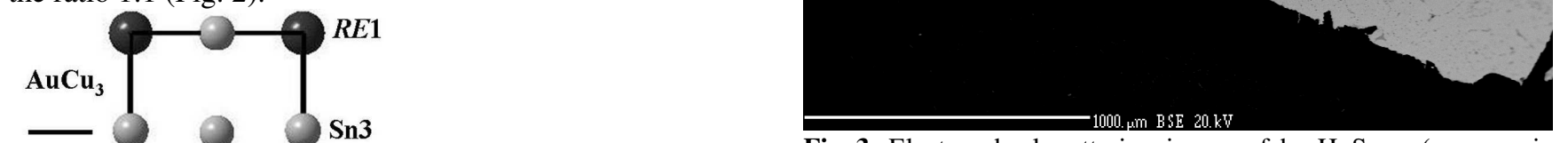

Fig. 3. Electron backscattering image of $\mathrm{hp}-\mathrm{HoSn}_{3-\mathrm{x}}$ (grey, main phase, $\mathrm{x}=0.3(2)$ ) containing traces of tin-rich solid solution $\mathrm{Sn}(\mathrm{Ho})$ (black spotty area top left).

Table 4. Starting composition, $P, T$-reaction conditions, identified phases and composition of the reaction products as determined by EDXS for phases hp-RESn ${ }_{3-\mathrm{x}}(R E=\mathrm{Tb}, \mathrm{Ho}, \mathrm{Er})$.

\begin{tabular}{|c|c|c|c|c|c|}
\hline $\begin{array}{l}\text { Starting } \\
\text { Comp. }\end{array}$ & $P / \mathrm{GPa}$ & & $T / \mathrm{K}$ & Phases & $\begin{array}{l}\text { Composition } \\
\text { EDX }\end{array}$ \\
\hline $\begin{array}{l}\text { Tb : Sn } \\
1: 3\end{array}$ & $\begin{array}{l}4.0(4) \\
5.7(6)\end{array}$ & - & $\begin{array}{l}920- \\
1270\end{array}$ & $\begin{array}{l}\text { hp-TbSn }{ }_{3-x} \\
\text { Sn }(\mathrm{Ho})\end{array}$ & $1: 2.7(2)$ \\
\hline $\begin{array}{l}\text { Ho : Sn } \\
1: 3\end{array}$ & $\begin{array}{l}5.7(6) \\
8.5(9) \\
\end{array}$ & - & $\begin{array}{l}870- \\
1270\end{array}$ & $\begin{array}{l}\text { hp-HoSn }{ }_{3-x} \\
\text { Sn(Ho) }\end{array}$ & \\
\hline $\begin{array}{l}\text { Ho }: \text { Sn } \\
1: 2.85\end{array}$ & $\begin{array}{l}5.7(6) \\
8.5(9)\end{array}$ & - & $\begin{array}{l}870- \\
1270\end{array}$ & $\begin{array}{l}\text { hp-HoSn } \\
\text { Sn(Ho) }\end{array}$ & $1: 2.7(2)$ \\
\hline $\begin{array}{l}\text { Er }: S n \\
1: 3\end{array}$ & $11(1)$ & & 1173 & $\begin{array}{l}\text { hp-ErSn } \\
\text { Sn(Ho) }\end{array}$ & \\
\hline
\end{tabular}

(Fig. 3). Reaction conditions for the preparation of highpressure phases hp-RESn ${ }_{3-\mathrm{x}}(R E=\mathrm{Tb}, \mathrm{Ho}, \mathrm{Er})$ are summarized in Table 4.

With respect to the crystal structures of the phases hp$R E \mathrm{Sn}_{3-\mathrm{x}}$ adopting a $\mathrm{Cu}_{3} \mathrm{Au}$-type atomic pattern, two idealized situations of these substitution varieties of an $f c c$ arrangement can be distinguished: A randomly disordered face-centred cubic crystal structure (space group $F m \overline{3} \mathrm{~m}$ ) and an -at least partially- site-ordered, primitive cubic arrangement (space group $P m \overline{3} m$ ). A synchrotron powder $\mathrm{X}$-ray diffraction measurement of a sample hp-HoSn $\mathrm{H}_{3-\mathrm{x}}$ with a nominal composition $1: 2.85$ reveals broad reflection profiles which are attributed to sample inhomogeneities. However, the presence of weak reflections, e.g., slightly above 6 degrees and 8 degrees two theta (Fig. 4), indicate a primitive cubic lattice.

Using the same thermal displacement parameter for both atomic positions, the refinements indicate an occupation of Wyckoff position $3 c(1 / 2,1 / 2,0)$ mainly by tin with s.o.f. $\mathrm{Sn}=0.95(1)$ and s.o.f. Ho $=0.05(1)$. For $1 a(0,0,0)$, the results converge to s.o.f. $\mathrm{Ho}=0.90(1)$ and s.o.f. $\mathrm{Sn}=0.05(1)$ indicating approximately $5 \%$ defects on position 1a. These refined occupancies result in a composition $\mathrm{HoSn}_{2.76(15)}$ consistent with the EDX results. Thus, contrary to the findings of the earlier investigation [12], the synchrotron diffraction data evidence that the highpressure phase $\mathrm{hp}-\mathrm{HoSn}_{3-\mathrm{x}}$ adopts a partially ordered $\mathrm{Cu}_{3} \mathrm{Au}$-type arrangement [16]. 


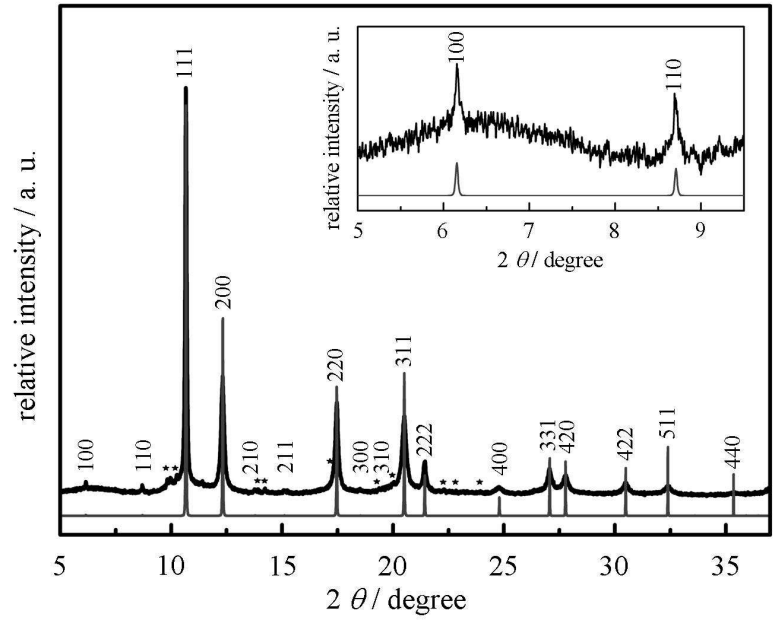

Fig. 4. Powder X-ray diffraction pattern of hp-HoSn $n_{3-x}$. The weak reflections (see inset) at above six and eight degrees, respectively, indicate a partially ordered arrangement of the holmium and tin atoms in a primitive cubic crystal structure. Stars indicate reflections of a tin-rich solid solution $\mathrm{Sn}(\mathrm{Ho})$ with $\beta$-Sn-like crystal structure.

In order to study the thermal stability of the cubic highpressure phase $\mathrm{hp}-\mathrm{HoSn}_{3-\mathrm{x}}$, differential scanning calorimetry measurements (Fig. 5) have been combined with temperature-dependent in-situ powder X-ray diffraction experiments (Fig. 6). The exothermic character of the first transition as revealed by DSC indicates a monotropic transformation. The diffraction data show that $\mathrm{Cu}_{3} \mathrm{Au}$-type hp-HoSn $n_{3-x}$ transforms into the low-pressure modification $\mathrm{HoSn}_{3-\mathrm{x}}\left(\mathrm{GdSn}_{3-\mathrm{x}}\right.$ type [13]) below $470 \mathrm{~K}$ (Fig. 7). The upper limit of the transition temperature of $450 \mathrm{~K}$ which is measured in the diffraction experiments is in good agreement with the onset temperature of $460 \mathrm{~K}$ as determined by DSC measurements. The remaining difference is assigned to the kinetic control of the transformation and the different heating rates. The effect at temperatures slightly above this transformation is attributed to the melting of tin-rich solid solution $\mathrm{Sn}(\mathrm{Ho})$. According to the phase diagram [14], lp-HoSn ${ }_{3-x}$ decomposes into $\mathrm{Ho}_{2} \mathrm{Sn}_{5}$ and a solid solution $\mathrm{Sn}(\mathrm{Ho})$ at $701 \mathrm{~K}$.

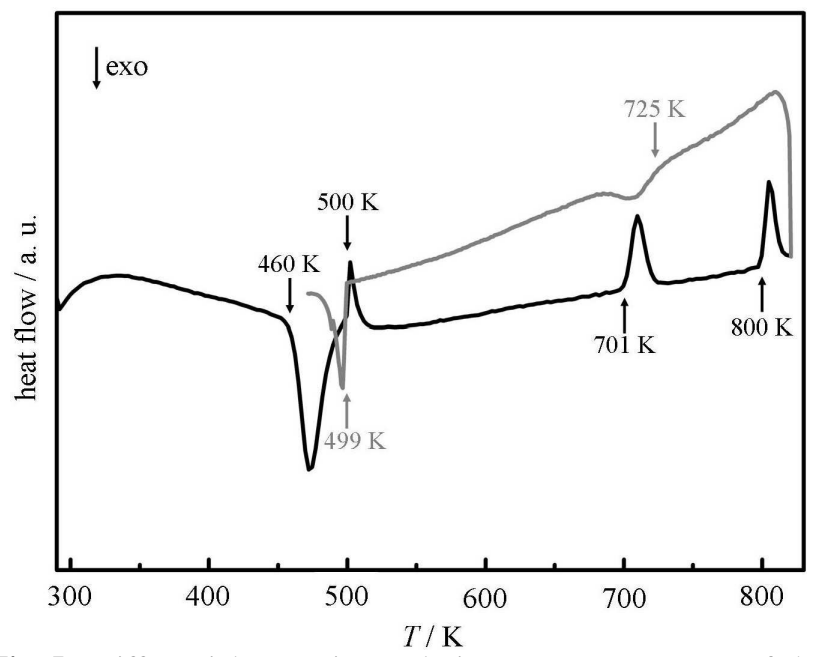

Fig. 5. Differential scanning calorimetry measurement of hp$\mathrm{HoSn}_{3-\mathrm{x}}$ using a heating rate of $10 \mathrm{~K} \mathrm{~min}^{-1}$. The exothermal effect at $460 \mathrm{~K}$ is attributed to the phase transition from $\mathrm{hp}-\mathrm{HoSn}_{3-\mathrm{x}}$ to the orthorhombic ambient pressure modification of $\mathrm{HoSn}_{3-\mathrm{x}}$. Black curve: increasing temperature; grey curve: decreasing $T$.

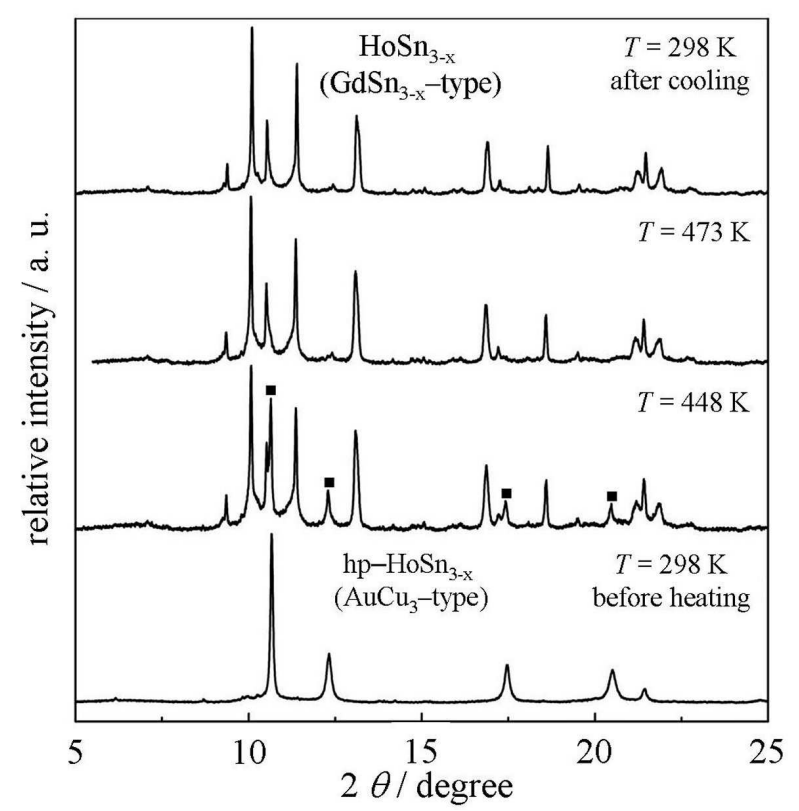

Fig. 6. Powder X-ray diffraction patterns of hp-HoSn $n_{3-\mathrm{x}}$ and its transformation products at elevated temperatures. The transformation of hp-HoSn ${ }_{3-\mathrm{x}}$ into $\mathrm{HoSn}_{3-\mathrm{x}}$ is already visible at $448 \mathrm{~K}$ and completed at $473 \mathrm{~K}$. In the pattern recorded in the transition range, squares indicate reflections of residual hp- $\mathrm{HoSn}_{3-\mathrm{x}}$.

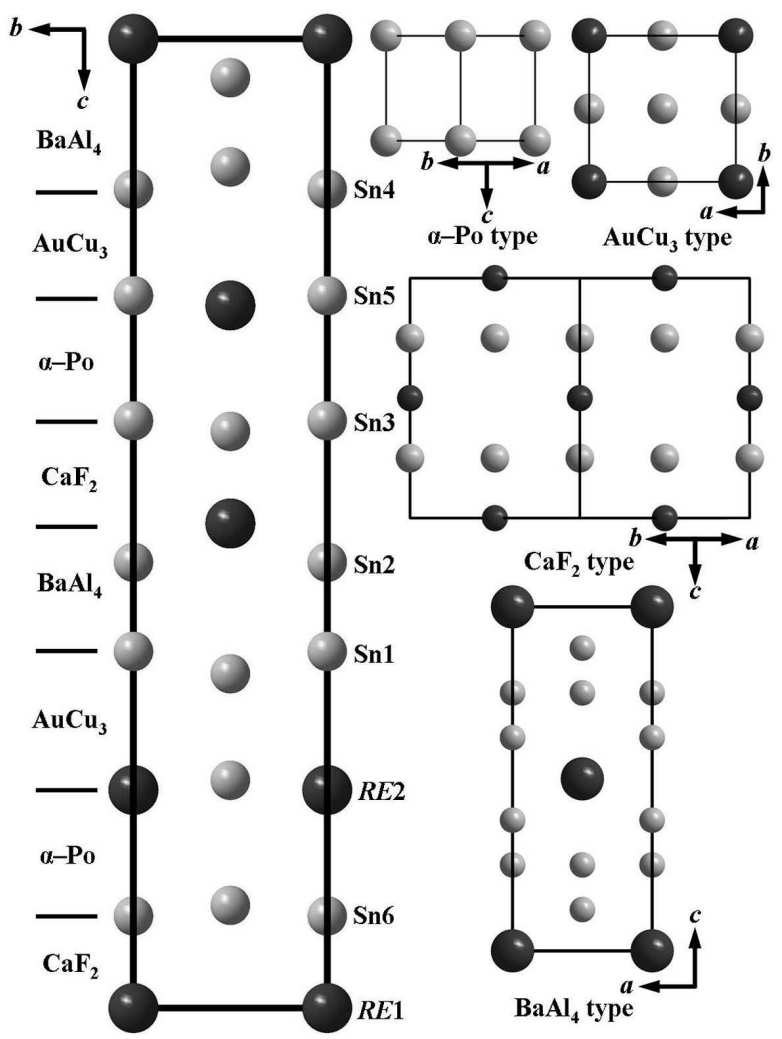

Fig. 7. Crystal structures of phases $R E \mathrm{Sn}_{3-\mathrm{x}}$ (left) isotypic to $\mathrm{GdSn}_{3-\mathrm{x}}$ [13] and the constituting segments (right). The phases hp$R E \mathrm{Sn}_{3-\mathrm{x}}$ are isotypic to $\mathrm{AuCu}_{3} .(R E=\mathrm{Tb}, \mathrm{Ho}, \mathrm{Er})$.

Finally, at $800 \mathrm{~K} \mathrm{Ho}_{2} \mathrm{Sn}_{5}$ decomposes into $\mathrm{HoSn}_{2}$ and a solid solution $\mathrm{Sn}(\mathrm{Ho})$ with $\beta$-Sn arrangement. Upon cooling the effect at $704 \mathrm{~K}$ is attributed to the crystallisation of a mixture of tin-rich holmium phases and that around $500 \mathrm{~K}$ to the recrystallization of the solid solution $\mathrm{Sn}(\mathrm{Ho})$ adopting a $\beta$-Sn pattern. In accordance with these assignments, powder X-ray diffraction data of samples measured after the 
heating cycle evidence the formation of a solid solution $\mathrm{Sn}(\mathrm{Ho})$ with $\beta$-Sn crystal structure, the compound $\mathrm{Ho}_{2} \mathrm{Sn}_{5}$ and a third phase. After reaching the maximum temperature of the experiment $(483 \mathrm{~K})$, the formed modification $\mathrm{HoSn}_{3-\mathrm{x}}$ remains stable upon cooling to ambient conditions indicating the metastable character of $\mathrm{hp}-\mathrm{HoSn}_{3-\mathrm{x}}$.

\section{Chemical bonding in $\mathrm{Er}_{3} \mathrm{Sn}_{7}$}

The differentiation within the structure fragments in phases $R E_{3} \mathrm{Sn}_{7}(R E=\mathrm{Tb}, \mathrm{Ho}, \mathrm{Er})$ facilitates different atomic interactions within the crystal structure. This indication was investigated by an analysis of the chemical bonding in direct space applying the electron localizability indicator technique.

In $\mathrm{Er}_{3} \mathrm{Sn}_{7}$, a characteristic feature of ELI within the $\mathrm{AlB}_{2}$ segment is the formation of maxima close to the $\mathrm{Sn}-\mathrm{Sn}$ contacts (Fig. 8 bottom) indicating $2 c$ (two-centre) Sn-Sn bonding. ELI attractors above and below each $\mathrm{Sn}$ atoms would reflect lone pairs if the zigzag chains were completely isolated. In the crystal structure of $R E_{3} \mathrm{Sn}_{7}$, they are attributed to multi-centre interactions. In all segments the bonds within mixed $R E$-Sn square nets have $3 c$ character (Fig. 8 top), in the square $\mathrm{Sn}$ nets $2 c \mathrm{Sn}-\mathrm{Sn}$ bonding is observed. The ELI attractors above and below the tin atoms indicate $5 c \mathrm{Sn}_{5}$ or $\mathrm{SnEr}_{4}$ interactions between adjacent nets.

The presence of multi-centre bonds suggests a rather metallic behaviour of the $R E_{3} \mathrm{Sn}_{7}$ phases. This is confirmed by the calculated total electronic density of states (Fig. 9). Even assuming a strongly localized character of the Er $4 f$ states, there is a significant density of states at the Fermi level originating from $\mathrm{Sn} 5 p$ states.

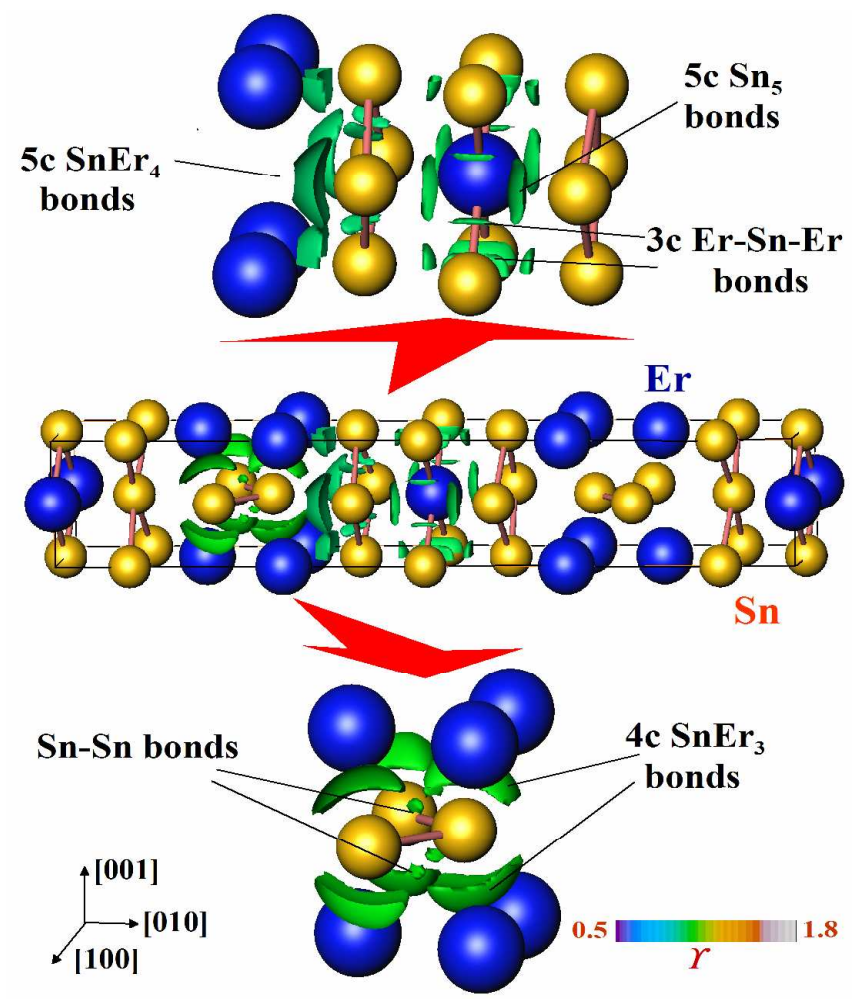

Fig. 8. Chemical bonding in $\mathrm{Er}_{3} \mathrm{Sn}_{7}$ : Distribution of the electron localizability indicator (ELI) within the $\mathrm{CaF}_{2^{-}}$and $\mathrm{AuCu}_{3}$-like segments (top) and the $\mathrm{AlB}_{2}$-like fragment (bottom) visualized by isosurfaces of $r=1.04, \quad r=1.07$ and $r=1.11$, respectively. Atomic arrangement and distribution of ELI in the unit cell of $\mathrm{Er}_{3} \mathrm{Sn}_{7}$ (middle).

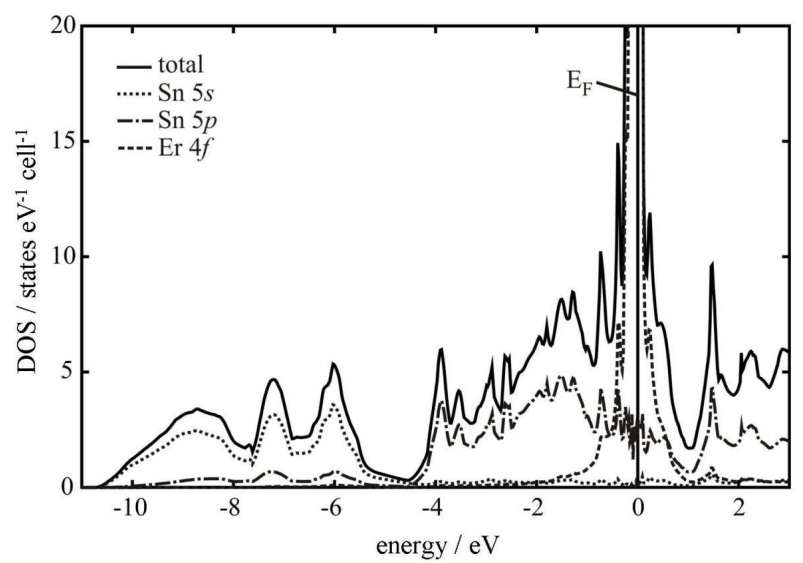

Fig. 9. Computed total electronic density of states (DOS) with partial atomic contributions for $\mathrm{Er}_{3} \mathrm{Sn}_{7}$.

\section{Physical properties of phases $\mathrm{RE}_{3} \mathrm{Sn}_{7}$ and $\mathrm{hp}-\mathrm{RESn_{3-x }}$}

With respect to the electronic states of the terbium compounds, X-ray absorption spectra reveal that the white line (WL) of $\mathrm{TbSn}_{3-\mathrm{x}}$ is located at the same position as the low-energy contribution of mixed-valent $\mathrm{Tb}_{4} \mathrm{O}_{7}$ $\left(\left[\mathrm{Tb}^{3+}\right]_{2}\left[\mathrm{~Tb}^{4+}\right]_{2} \mathrm{O}_{7}\right)$ and coincides within the experimental resolution of $1 \mathrm{eV}$ with the $\mathrm{WL}$ of $\mathrm{Tb}^{3+} \mathrm{PO}_{4}$ (Fig. 10). Consequently, terbium is assigned to the electronic state $4 f^{8}$. In $\mathrm{Tb}_{3} \mathrm{Sn}_{7}$, the WL is located at the same position as that of $\mathrm{Tb}^{3+} \mathrm{PO}_{4}$ also evidencing $\mathrm{Tb}^{3+}$.

The magnetic susceptibilities $\chi(T)=M / H$ of hp-HoSn $n_{3-\mathrm{x}}$ and $\mathrm{Ho}_{3} \mathrm{Sn}_{7}$ are well described by a Curie-Weiss law at high temperatures (Fig. 11 top). From fits to the data above $20 \mathrm{~K}$ the following effective moments and paramagnetic Weiss temperatures are obtained: $\operatorname{HoSn}_{2.85}, \quad \mu_{\text {eff }}=10.46 \mu_{\mathrm{B}}$, $\theta_{\mathrm{P}}=-14.9 \mathrm{~K} ; \mathrm{Ho}_{3} \mathrm{Sn}_{7}, \mu_{\text {eff }}=10.54 \mu_{\mathrm{B}}, \theta_{\mathrm{P}}=-10.5 \mathrm{~K}$. The observed behaviour confirms the presence of trivalent Ho ions with $4 f^{10}$ configuration ( ${ }^{5} I_{8}$ multiplet, $\left.\mu_{\text {free }}=10.61 \mu_{\mathrm{B}}\right)$
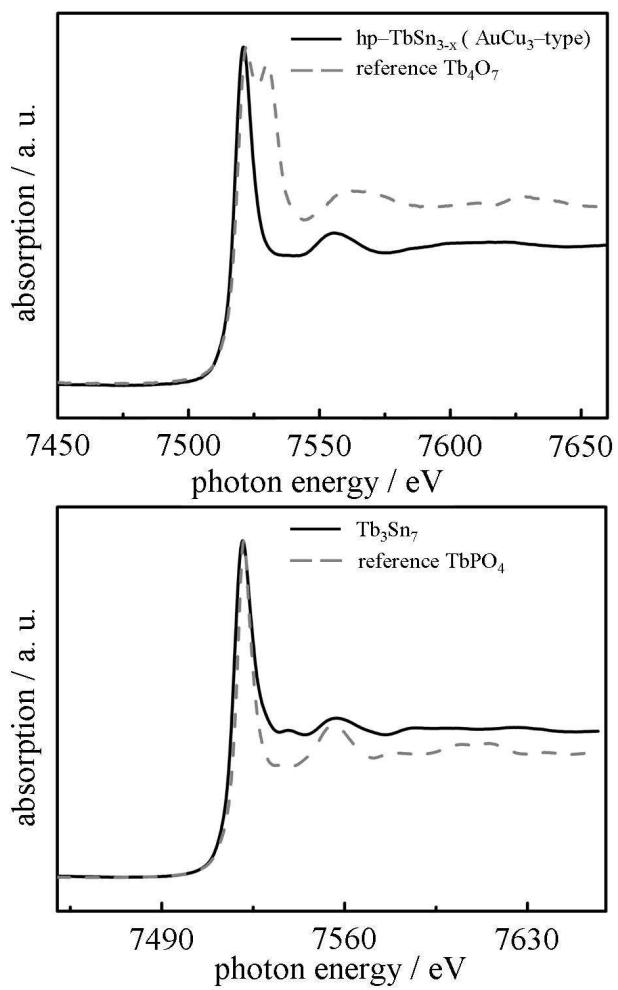

Fig. 10. X-ray absorption spectra of hp- $\mathrm{TbSn}_{3-\mathrm{x}}$ (top) and $\mathrm{Tb}_{3} \mathrm{Sn}_{7}$ (bottom) indicating a $4 f^{8}$ configuration of terbium in both compounds consistent with the oxidation state $\mathrm{Tb}^{3+}$. 


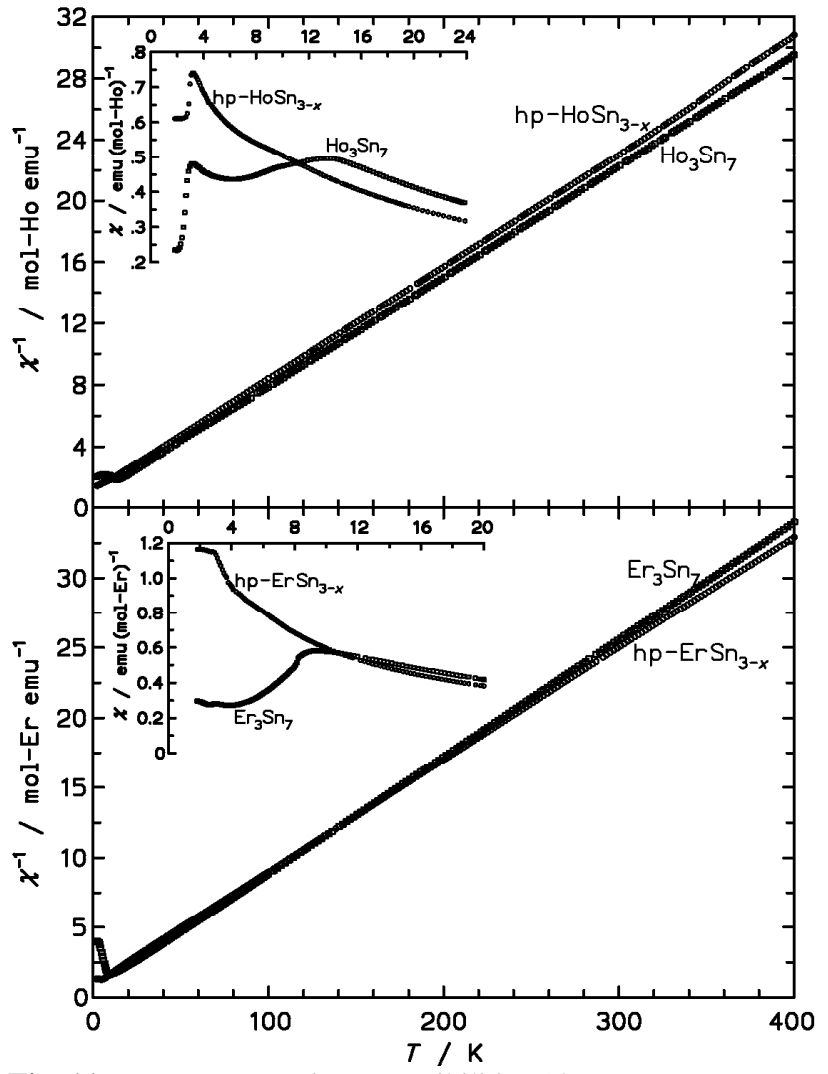

Fig. 11. Inverse magnetic susceptibilities $1 / \chi$ versus temperature $T$ for polycrystalline samples of $\mathrm{hp}-\mathrm{HoSn}_{3-\mathrm{x}}$ and $\mathrm{Ho}_{3} \mathrm{Sn}_{7}$ (top) as well as hp-ErSn ${ }_{3-\mathrm{x}}$ and $\mathrm{Er}_{3} \mathrm{Sn}_{7}$ (bottom) in a field $\mu_{0} H=1 \mathrm{~T}$. The insets show $\chi(T)$ for low temperatures and $\mu_{0} H=0.01 \mathrm{~T}$.

and suggests antiferromagnetic interactions. A broad cusp in $\chi(T)$ due to antiferromagnetic ordering of the Ho moments is observed (Fig. 11 top, inset) at $T_{\mathrm{N}}=13.6 \mathrm{~K}$ for $\mathrm{Ho}_{3} \mathrm{Sn}_{7}$. For $\mathrm{hp}-\mathrm{HoSn}_{3-\mathrm{x}}$ no sharp anomaly but only a very broad hump is visible at approximately $10 \mathrm{~K}$.

In isothermal magnetization curves measured at $T=1.8 \mathrm{~K}$ on both holmium compounds $M(H)$ increases sub-linearly up to $\sim 2 \mathrm{~T}$ and then becomes linear. Saturation is not reached for the maximum field (hp-HoSn ${ }_{3-\mathrm{x}}: M(7 \mathrm{~T})$ $\left.\sim 5.1 \mu_{\mathrm{B}} ; \mathrm{Ho}_{3} \mathrm{Sn}_{7}: M(7 \mathrm{~T}) \sim 4.3 \mu_{\mathrm{B}} ;\right)$. The presence of tin at the grain boundaries of both samples is concluded from a superconducting transition at $3.6 \mathrm{~K}$ in a field of $1 \mathrm{mT}$. As can be deduced from the field-cooling Meissner effect the volume of $\mathrm{Sn}$ metal is small (flux expulsion $<1 \%$ ), however the shielding (zero-field cooling) of the crystallites of the main phase by the surrounding superconducting tin is almost perfect. The electrical resistivity $\rho(T)$ of the hp$\mathrm{HoSn}_{3-\mathrm{x}}$ sample is typically metallic with a room temperature value $\rho(300 \mathrm{~K})=31 \mu \Omega \mathrm{cm}$ and a residual resistivity $\rho_{0}=2.1 \mu \Omega \mathrm{cm}$. In accordance with the susceptibility data, no sharp anomaly is visible in $\rho(T)$ (especially not around $10 \mathrm{~K}$ ) which would indicate a magnetic ordering of the moments in residual elemental holmium. The Er compounds also show Curie-Weiss behaviour at elevated temperatures (Fig. 11 bottom). Fits above $50 \mathrm{~K}$ yield for $\mathrm{ErSn}_{3} \mu_{\mathrm{eff}}=10.00 \mu_{\mathrm{B}}$ and $\theta_{\mathrm{P}}=-12.4 \mathrm{~K}$ and for $\mathrm{Er}_{3} \mathrm{Sn}_{7} \mu_{\mathrm{eff}}=9.79 \mu_{\mathrm{B}}$ and $\theta_{\mathrm{P}}=-6.3 \mathrm{~K}$. Thus, the Er ions have the $4 f^{11}$ configuration $\left({ }^{4} \mathrm{I}_{5 / 2}\right.$ ground state, $\mu_{\text {free }}=9.58 \mu_{\mathrm{B}}, \quad \mathrm{Er}^{3+}$ ) and interact predominantly antiferromagnetic. While for $\mathrm{hp}-\mathrm{ErSn}_{3-\mathrm{x}}$ again no signature of magnetic ordering is found, there is a clear but broad cusp at $8.2(3) \mathrm{K}$ suggesting an antiferromagnetic ordering in $\mathrm{Er}_{3} \mathrm{Sn}_{7}$. The isothermal magnetization curve of hp-ErSn $\mathrm{En}_{3-\mathrm{x}}$ $(T=1.8 \mathrm{~K})$ tends to saturate for $\mu_{0} H=7 \mathrm{~T}$ at $\approx 6.6 \mu_{\mathrm{B}}$ which is well below the theoretical value $g J=9 \mu_{\mathrm{B}}$ for the multiplet. For $\mathrm{Er}_{3} \mathrm{Sn}_{7}$ a similar value of $M(7 \mathrm{~T})$ per Er atom is observed, however, there is a very broad metamagnetic transition between $0.8 \mathrm{~T}$

and $\approx 4.0 \mathrm{~T}$ which has a field hysteresis. According to lowfield data there is only little free tin in the samples of the Er compounds, but more homogeneous samples of all phases are required for further investigations of the magnetism.

\section{Summary}

Phases $R E_{3} \mathrm{Sn}_{7}$ and hp-RESn $\mathrm{n}_{3-\mathrm{x}}(R E=\mathrm{Tb}, \mathrm{Ho}$ and $\mathrm{Er})$ adopting $\mathrm{Gd}_{3} \mathrm{Sn}_{7}$-type and $\mathrm{Cu}_{3} \mathrm{Au}$-type crystal structures, respectively, were synthesized at high-pressure hightemperature conditions. For hp-HoSn $n_{3-\mathrm{x}}$, a partially ordered $\mathrm{Cu}_{3} \mathrm{Au}$-type with defects is verified. Measurements of the magnetic susceptibilities and X-ray absorption spectra evidence oxidation state +3 for the rare-earth metal atoms in all investigated compounds. A study of the chemical bonding in $\mathrm{Er}_{3} \mathrm{Sn}_{7}$ by the electron localizability approach reveals multi-centre tin-tin and tin-rare earth interactions. In zig-zag chains formed by tin, two-centre bonding is observed.

\section{Experimental Section}

Preparation of the precursors by arc melting and sample handling is performed in argon-filled glove boxes (MBraun, $\mathrm{H}_{2} \mathrm{O}<0.1 \mathrm{ppm}$; $\mathrm{O}_{2}<0.1 \mathrm{ppm}$ ). In order to avoid contamination with oxygen or moisture, the high-pressure assembly is transferred to the press directly before synthesis. After the experiment, the set-up is immediately removed from the Walker module and transported into a glove box where the sample is recovered from the crucible.

High-pressure and high-temperature preparation experiments are performed in an octahedral assembly. The redistribution of the uniaxial force of the hydraulic press is realized by a Walker module with inserted $\mathrm{MgO}$ octahedra of $14 \mathrm{~mm}$ edge length [20]. Elevated temperatures are realized by resistive heating in a graphite cylinder. Pressure and temperature calibration is performed prior to the experiments by in-situ monitoring of the resistance changes of bismuth [21] and by adjusting the heating power with a thermocouple, respectively. Typical annealing times amount to $2 \mathrm{~h}$. As crucible material served hexagonal boron nitride. At the reaction conditions, the containers remain inert in contact to the samples as evidenced by X-ray powder diffraction data and energy dispersive X-ray analysis, respectively. For the high-pressure syntheses, typical annealing times amount to two hours. Quenching to ambient temperature is realized by disconnecting the heating current before decompression.

In order to investigate the phase distribution within the samples by light- and electron-optical microscopy on metallographic microstructures, the air and moisture sensitive samples are prepared in an inert gas atmosphere of a glove box using dried hexane as lubricant. The compositions of the phases are determined by energy dispersive $\mathrm{x}$-ray spectrometry (Phoenix system, EDAX) on a scanning electron microscope (FEI XL30). The X-ray spectra have been collected with an acceleration voltage of $25 \mathrm{kV}$. The semiquantitative analyses using X-ray intensities of the Ho $L(6.72 \mathrm{keV})$ and the $\mathrm{Sn} L(3.44 \mathrm{keV})$ lines yield for, e.g., $\mathrm{HoSn}_{3-\mathrm{x}}$ the following composition after matrix correction according to the ZAF model: Ho: 29.1(6) at.\% and Sn: 70.9(6) at.\%. The accuracy is estimated from the relative error of Ho $L$ and $\mathrm{Sn} L$ intensities $\mathrm{d} I / I=1.6 \%$ and $0.1 \%$, respectively. The variation of the intensity of the Ho $L$ line corresponds to $0.6 \mathrm{wt} . \%$ assuming a linear relation between $\mathrm{X}$-ray 
intensity and Ho content (in wt.\%). Presence and composition of additional phases like $\beta$-Sn-type solid solutions is also verified by EDXS analysis.

$\mathrm{X}$-ray powder diffraction data are collected in transmission alignment with a Huber Image Plate Guinier Camera G670 employing $\mathrm{Cu} K \alpha_{1}$ radiation $(\lambda=1.54056 \AA$ ). In order to avoid oxidation during powder preparation, samples are ground in an inert atmosphere. After adding $\mathrm{LaB}_{6}$ as an internal standard $(a=$ $4.1569 \AA$ ) the mixture is fixed between two mylar foils. For lattice parameters refinements sets of about $5\left(R E \mathrm{Sn}_{3-\mathrm{x}}\right)$ or $10\left(R E_{3} \mathrm{Sn}_{7}\right)$ reflections are used. WinXPOW was used for phase identification on the basis of X-ray powder diffraction data [22]. Profile fitting and lattice parameter calculations are performed with the program package WINCSD [23]. Structure visualisation is realized by means of the computer program DIAMOND [24].

The in-situ high-temperature diffraction experiments were performed at the Beamline B2 of HASYLAB at DESY in the temperature range from $298 \mathrm{~K}$ to $483 \mathrm{~K}$ with a powder diffractometer equipped with an on-site readable image plate detector OBI [25] and a STOE furnace. The wavelength ( $\lambda=0.49953 \AA$ ) was calibrated using the reflection positions of a silicon reference material (NIST SRM 640b). The polycrystalline powdered sample was filled in a quartz glass capillary under inert gas atmosphere and closed with two-components adhesive.

Differential Scanning Calorimetry (DSC) measurements at ambient pressure are performed with a Netzsch STA 449 C equipment using $\mathrm{Al}_{2} \mathrm{O}_{3}$ crucibles at temperatures between 295 and $1473 \mathrm{~K}$.

Electronic structure calculation and bonding analysis were carried out for $\mathrm{Er}_{3} \mathrm{Sn}_{7}$ using the TB-LMTO-ASA program package [26]. The ordered model was used for calculations with the position of Sn4 being completely occupied. The Barth-Hedin exchange potential [27] was employed for the LDA calculations. The radial scalar-relativistic Dirac equation was solved to get the partial waves. Because the calculation within the atomic sphere approximation (ASA) includes corrections for the neglect of interstitial regions and partial waves of higher order [28] an addition of empty spheres was not necessary. The following radii of the atomic spheres were applied for the calculations: $r(\operatorname{Er} 1)=$ $184.8 \mathrm{pm}, r(\mathrm{Er} 2)=194.1 \mathrm{pm}, r(\mathrm{Sn} 1)=180.2 \mathrm{pm}, r(\mathrm{Sn} 2)=182.7$ $\mathrm{pm}, r(\mathrm{Sn} 3)=182.7 \mathrm{pm}, r(\mathrm{Sn} 4)=161.9 \mathrm{pm}$. A basis set containing $\operatorname{Er}(6 s, 5 d, 4 f)$ and $\operatorname{Sn}(5 s, 5 p)$ orbitals was employed for a selfconsistent calculation with $\operatorname{Er}(6 p)$, and $\operatorname{Sn}(5 d, 4 f)$ functions being downfolded. The calculations were performed in a spin-polarized manner. The electron localizability indicator (ELI, Y) [29] was evaluated in the ELI-D representation according to Refs. [30, 31] with an ELI-D module within the TB-LMTO-ASA [26] program package.

The magnetization of polycrystalline samples was measured at external fields $\mu_{0} H$ between $1 \mathrm{mT}$ and $7 \mathrm{~T}$ (temperature range $1.8 \mathrm{~K}-400 \mathrm{~K}$ ) in a SQUID magnetometer (MPMS XL-7, Quantum Design). The electrical resistivity $\rho(T)$ of $\mathrm{HoSn}_{3}$ was determined by a dc four-point method $(4 \mathrm{~K}-320 \mathrm{~K})$. Due to the small size of the sample the inaccuracy of the absolute resistivity values is estimated to be $\pm 30 \%$.

The valence state of $\mathrm{Tb}$ was investigated by X-ray absorption spectroscopy at the $\mathrm{Tb} L_{\mathrm{III}}$ edge. The spectra were recorded in transmission arrangement at the EXAFS Beamline E4 of the Hamburg synchrotron radiation laboratory (HASYLAB) at DESY. Wavelength selection was realized by means of a $\mathrm{Si}(111)$ double crystal monochromator which yields an experimental resolution of approximately $1.0 \mathrm{eV}$ for the experimental setup at the $\mathrm{Tb} L_{\mathrm{III}}$ edge threshold of $7514 \mathrm{eV}$. Polycrystalline sample were mixed under argon atmosphere with $\mathrm{B}_{4} \mathrm{C}$ and filled in a stainless steal cell with beryllium windows. The Experimental data were measured using $\mathrm{TbPO}_{4}$ or $\mathrm{Tb}_{4} \mathrm{O}_{7}$ as external references.

\section{Acknowledgments}

The authors thank Mrs. Susann Leipe for supporting high pressure synthesis, Dr. Stefan Hoffmann and Mrs. Susann Scharsach for the DSC measurements, and Dr. D. Trots for assistance in the powder $\mathrm{X}$-ray synchrotron diffraction experiments at HASYLAB (project II-20060043). We thank Dr. Yurii Prots and Dr. Roman Gumeniuk for helpful discussions. U.S. gratefully acknowledges nocturnal conversations with Bernd, e.g., under a blue Caribbean sky.

[1] A. Wosylus, Yu. Prots, U. Burkhardt, W. Schnelle, U. Schwarz, Yu. Grin, Solid State Sciences 2006, 8, 773

[2] A. Wosylus, Yu. Prots, U. Burkhardt, W. Schnelle, U. Schwarz, Yu. Grin, Z. Naturforsch. 2006, 61b, 1485.

[3] A. Wosylus, Yu. Prots, U. Burkhardt, W. Schnelle, U. Schwarz, Science and Technology of Advanced Materials 2007, 8, 383.

[4] R. Demchyna, S. Leoni, H. Rosner, U. Schwarz, Z. Kristallogr. 2006, 221, 420

[5] S. Yamanaka, S. Maekawa, Z. Naturforsch. B 2006, 61, 1493.

[6] A. Wosylus, R. Demchyna, Yu. Prots, U. Schwarz, Z. Kristallogr. NCS 2009, 224, 347.

[7] K. Meier, A. Kerkau, U. Schwarz, Z. Kristallogr. NCS 2009, 224, 373.

[8] K. Meier, C. Koz, A. Kerkau, U. Schwarz, Z. Kristallogr. NCS 2009, 224, 349.

[9] K. Meier, R. Cardoso-Gil, W. Schnelle, H. Rosner, U.

Burkhardt, U. Schwarz, Z. Anorg. Allg. Chem, submtted.

[10] H. Fukuoka, S. Yamanaka, Phys. Rev. B 2003, 67, 094501.

[11] H. Fukuoka, K. Baba, M. Yoshikawa, F. Ohtsu, S. Yamanaka, J. Solid State Chem. 2009, 182, 2024.

[12] K. Miller and T. Hall, Inorg. Chem. 1972, 11, 1188.

[13] R. V. Skolozdra, L. G. Akselrud, V. K. Pecharsky, O. E. Koretskaya, Dopov. Akad. Nauk Ukr. RSR, Ser. B 1986, 12, 48.

[14] A. Palenzona, P. Manfrinetti, J. Alloys. Comp. 1993, 201, 43.

[15] A. Iandelli, A. Palenzona, Atti. Accad. Nazl. Lincei, Rend. Cl. Sci. Fis. Mat. Nat. 1966, 40, 623.

[16] In some databases the space group of the $\mathrm{Cu}_{3} \mathrm{Au}$-type hpphases $R E \mathrm{Sn}_{3}(\mathrm{RE}=\mathrm{Y}$; Tb, Dy, Ho, Er) is given as $P m \overline{3} m$ while in the original contribution the modification is described as disordered in space group $F m \overline{3} m$ [12].

[17] Yu. Grin, Ya. P. Yarmolyuk, E. I. Gladyshevski. Sov. Phys. Crystallogr. 1982, 27, 413.

[18] E. Parthe, B. Chabot, K. Cenzual. Chimia, 1985, 39, 164.

[19] M. Pani, M.-L. Fornasini, Z. Kristallogr. 1990, 190, 127.

[20] D. Walker, M. A. Carpenter, C. M. Hitch, Am. Mineral. 1990, $75,1020$.

[21] D. A. Young. Phase diagrams of the elements. UC Press, 1991.

[22] WinXPow. Powder diffraction software, Stoe \& Cie., Darmstadt, Germany, 1999.

[23] CSD: L. G. Akselrud, P. Y. Zavalij, Yu. N. Grin, V. K. Pecharsky, B. Baumgartner, E. Wölfel, Material Science Forum 1993, 133, 335.

[24] DIAMOND 3, Crystal and molecular structure visualization, Crystal Impact, GbR, Bonn, 2009.

[25] M. Knapp, V. Joco, C. Baehtz, H. H.. Brecht, A. Ehrenberg, H. Seggern, H. Fuess, Nucl. Instrum. Methods. A 2004, 521, 565.

[26] O. Jepsen, A. Burkhardt, O. K. Andersen, The Program TBLMTO-ASA. Version 4.7. Max-Planck-Institut für Festkörperforschung, Stuttgart, 1999.

[27] U. von Barth, L. Hedin, J. Phys. 1972, C5, 1629.

[28] O. K. Andersen, Phys. Rev. B 1975, 12, 3060.

[29] M. Kohout, Int. J. Quantum Chem. 2004, 97, 651.

[30] M. Kohout, F. R. Wagner, Yu. Grin, Int. J. Quantum Chem. 2006, 106, 1499.

[31] M. Kohout, Faraday Disscuss. 2007, 135, 43.

Received: ((will be filled in by the editorial staff)) Published online: ((will be filled in by the editorial staff)) 
